\title{
Airborne black carbon variations during the COVID-19 lockdown in the Yangtze River Delta megacities suggest actions to curb global warming
}

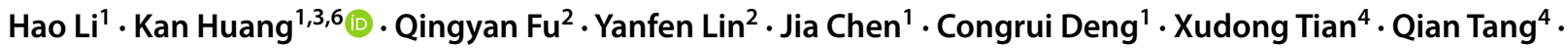 \\ Qingchuan Song ${ }^{4} \cdot$ Zhen Wei $^{5}$
}

Received: 7 June 2021 / Accepted: 13 September 2021 / Published online: 21 September 2021

(c) The Author(s), under exclusive licence to Springer Nature Switzerland AG 2021

\begin{abstract}
Airborne black carbon is a strong warming component of the atmosphere. Therefore, curbing black carbon emissions should slow down global warming. The 2019 coronavirus pandemic (COVID-19) is a unique opportunity for studying the response of black carbon to the varied human activities, in particular due to lockdown policies. Actually, there is few knowledge on the variations of black carbon in China during lockdowns. Here, we studied the concentrations of particulate matter $\left(\mathrm{PM}_{2.5}\right)$ and black carbon before, during, and after the lockdown in nine sites of the Yangtze River Delta in Eastern China. Results show 40-60\% reduction of $\mathrm{PM}_{2.5}$ and 40-50\% reduction of black carbon during the lockdown. The classical bimodal peaks of black carbon in the morning and evening rush hours were highly weakened, indicating the substantial decrease of traffic activities. Contributions from fossil fuels combustion to black carbon decreased about 5-10\% during the lockdown. Spatial correlation analysis indicated the clustering of the multi-site black carbon concentrations in the Yangtze River Delta during the lockdown. Overall, control of emissions from traffic and industrial activities should be efficient to curb black carbon levels in the frame of a 'green public transit system' for mega-city clusters such as the Yangtze River Delta.
\end{abstract}

Keywords COVID-19 $\cdot$ Black carbon $\cdot$ Lockdown $\cdot$ Spatial correlation $\cdot$ Yangtze River Delta

\section{Introduction}

Kan Huang

huangkan@fudan.edu.cn

Qingyan Fu

qingyanf@sheemc.cn

1 Shanghai Key Laboratory of Atmospheric Particle Pollution and Prevention (LAP3), Department of Environmental Science and Engineering, Fudan University, Shanghai 200433, China

2 Shanghai Environmental Monitoring Center, Shanghai 200030, China

3 IRDR ICoE On Risk Interconnectivity and Governance On Weather/Climate Extremes Impact and Public Health, Fudan University, Shanghai 200433, China

4 Zhejiang Ecological and Environmental Monitoring Center, Hangzhou 310012, Zhejiang, China

5 Anhui Ecological and Environmental Monitoring Center, Hefei 230071, Anhui, China

6 Institute of Eco-Chongming (IEC), Shanghai 202162, China
Airborne black carbon is thought to be the second largest contributor to global warming only inferior to carbon dioxide with a positive radiative forcing of $1.1 \mathrm{Wm}^{-2}$ (Bond et al. 2013). Black carbon is mainly emitted from incomplete combustion of biomass and fossil fuels, such as agriculture wastes, residential solid fuels, industrial coal, gasoline, and diesel (Bond et al. 2013; Briggs and Long 2016; Zhao et al. 2015). Black carbon pollution and its source apportionment have been reported in multiple studies, showing that black carbon had negative effects on air quality and could be one of the important inducing factors for the outbreak of haze (Huang et al. 2012; Liu et al. 2018; Wei et al. 2020).

At the beginning of 2020, a novel coronavirus (COVID19) was discovered and quickly spread among humans. SARS-CoV-2 could survive in the air, on the surfaces, in water and wastewater, and closely linked to the environment (Sharma et al. 2020). It had caused more than 10 million infections and 0.5 million deaths worldwide from January to April. This infectious disease brought huge socio-economic 
obstacles and disrupted normal society and human's living activities. In order to control the fast spread of COVID-19, the Chinese government constrained both the unnecessary travel and enterprise operations, and most people were required to stay at home since later January 2020 (Tian et al. 2020; Wang et al. 2020a). As a result, human activities were greatly reduced, hence minimizing anthropogenic emissions, including vehicles emissions, industrial emissions, etc. Thereafter, various lockdown policies have since been adopted worldwide, indirectly changing the atmospheric compositions.

A global simulation study by Earth System Models (ESMs) reported that the aerosol changes due to the COVID19 lockdown contributed the most to radiative forcing as well as temperature, even larger than ozone, $\mathrm{CO}_{2}$ and contrail effects. The average Effective Radiative Forcing (ERF) peaked at $+0.29 \pm 0.15 \mathrm{Wm}^{-2}$ in the spring of 2020 , attributable to the reductions of black carbon and sulfate, leading to decreases of total anthropogenic aerosol cooling through aerosol-cloud interaction (Gettelman et al. 2021). In terms of China, Li et al. (2020) reported that concentrations of sulfur dioxide $\left(\mathrm{SO}_{2}\right)$, nitrogen dioxide $\left(\mathrm{NO}_{2}\right)$, particles with aerodynamic diameters less than $2.5 \mu \mathrm{m}\left(\mathrm{PM}_{2.5}\right)$, and volatile organic compounds (VOCs) were reduced by $26,47,46$, and $57 \%$, respectively, during the strictest lockdown period over the Yangtze River Delta region. Huang et al. (2021) showed that $\mathrm{NO}_{\mathrm{x}}\left(\mathrm{NO}_{\mathrm{x}}=\mathrm{NO}_{2}+\mathrm{NO}\right)$ emissions reduced more than $60 \%$ in eastern China as well as for carbon monoxide (CO) and $\mathrm{SO}_{2}$. A similar downward trend of air pollutants was also observed in eastern China (Wang et al. 2020b). Bauwens et al. (2020) showed that tropospheric $\mathrm{NO}_{2}$ columns decreased approximately $65 \%$ over eastern China compared to the same period in 2019 based on TROPOMI (The Tropospheric Monitoring Instrument) onboard the Sentinel 5P satellite. Tanvir et al. (2021) revealed that vertical column densities (VCDs) of formaldehyde decreased 24\% during the strictest lockdown period. Although significant reductions of primary pollutants were found, ozone over eastern and northern China significantly rebounded during the lockdown (Yuan et al. 2021; Zhao et al. 2021; Zheng et al. 2021; Zhu et al. 2021). As a result, the enhanced role of secondary formation in haze formation was revealed (Chang et al. 2020; Huang et al. 2021; Le et al. 2020; Meng et al. 2021).

As one of the most climate-relevant atmospheric components, the unintended emission reduction caused by COVID19 lockdown provided a unique opportunity to understand the impact of controlled anthropogenic emissions on black carbon. The impact of this epidemic is worldwide, not just in China (Cai et al. 2021). An average decrease of $11 \%$ black carbon was seen for the whole Europe during the lockdown, with the different extents in France (42\%), Germany (21\%), UK (13\%), Spain (11\%), and Italy (8\%). The reduction of black carbon even reached $78 \%$ in Delhi, India (Evangeliou et al. 2021; Goel et al. 2021). In China, ambient black carbon showed decreases of $10 \%$ in northern China (Wang et al. 2021c), 41\% in Nanjing (Lin et al. 2021), 53\% in Suzhou (Wang et al. 2021a), and 44\% in Hangzhou (Xu et al. 2020), respectively.

Earlier studies on black carbon during the COVID-19 period mostly focused on observations over a limited geographic scale. However, little is known about the variations of black carbon emissions at the regional scale. In this study, real-time observations of black carbon at 9 sites in the Yangtze River Delta region, including urban, suburban, rural and background sites, were conducted to pinpoint the variations of black carbon concentrations, diurnal patterns, and sources. The different extents of black carbon in response to lockdown policies were assessed. Characteristics of black carbon at the city level were revealed by the city-dependent lockdown measures and local emission intensities and sources. Global Moran's I analysis was applied to assess the spatial correlation of black carbon during various periods. The similarity and dissimilarity of regional black carbon had been well explained by the lockdown measures during different stages. This study provided insights for the benefits from large scale air pollutants emission reduction and importance of designing sound strategies of joint prevention and control for regional pollution.

\section{Experimental}

\section{Observation network of airborne particles in the Yangtze River Delta region}

In this study, an observation network was established in the Yangtze River Delta region (Fig. 1), including three sites in Shanghai (Pudong, Dianshan Lake, and Chongming), three sites in Zhejiang province (Jinhua, Hangzhou, and Shanxi), two sites in Jiangsu province (Nanjing and Changzhou), and one site in Anhui province (Hefei). Details of the nine sites are given in Table $\mathrm{S} 1$.

\section{Measurement of black carbon and $\mathrm{PM}_{2.5}$ and source apportionment of black carbon}

Black carbon mass concentrations were measured by multiwavelength Aethalometer (AE-33, Magee Scientific, USA). Optical attenuation (ATN) of aerosol particles were measured with 1- min temporal resolution. The absorption coefficient $\left(b_{\mathrm{abs}}, \mathrm{Mm}^{-1}\right)$ was measured at seven wavelengths (370, $470,520,590,660,880$, and $950 \mathrm{~nm}$ ), and the black carbon concentration was calculated by the optical attenuation at $880 \mathrm{~nm}$ using the mass absorption cross section (MAC) with the value of $\mathrm{MAC}_{880 \mathrm{~nm}}=7.77 \mathrm{~m}^{2} \mathrm{~g}^{-1}$. 


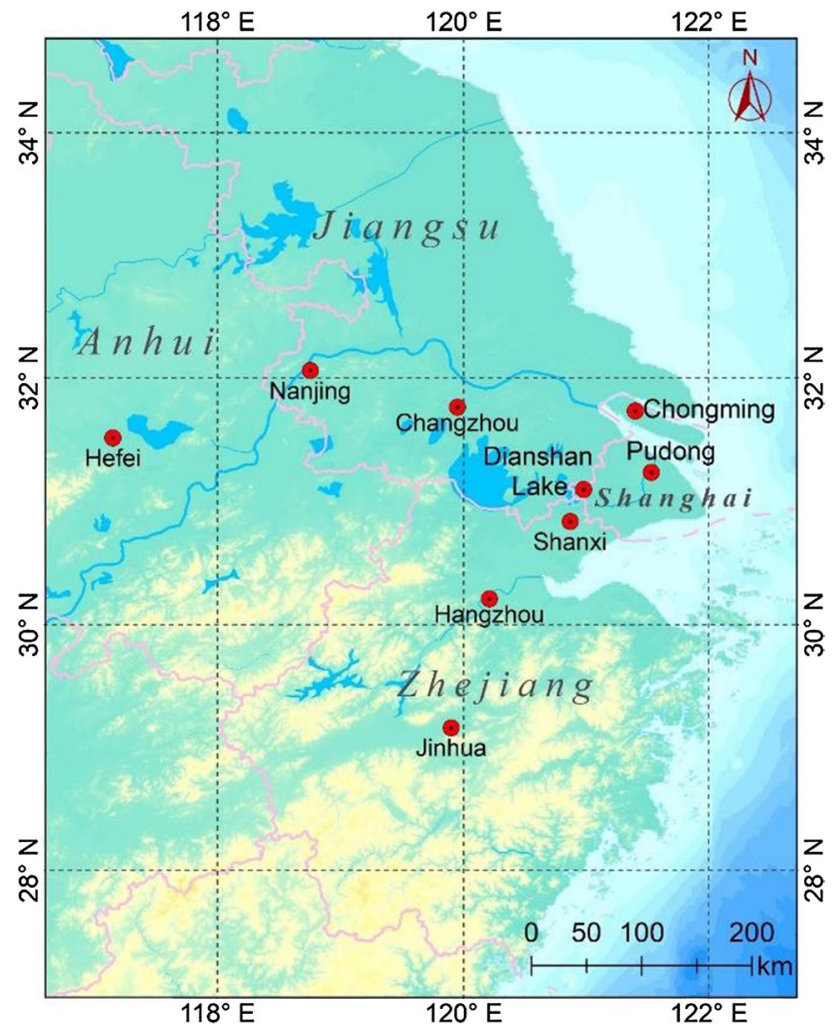

Fig. 1 Location of the 9 observation sites in the Yangtze River Delta region

$\mathrm{b}_{\mathrm{atn}}=\frac{\mathrm{S} \times(\Delta \mathrm{ATN} / 100)}{\mathrm{F}_{\mathrm{in}} \Delta \mathrm{t}}$

$b_{\mathrm{abs}}=\frac{b_{\mathrm{atn}}}{\mathrm{C}}$

$\mathrm{C}_{\mathrm{BC}}=\frac{b_{\mathrm{abs}}}{\mathrm{MAC}}$

where $b_{a t n}$ is the optical attenuation coefficient; $S$ refers to spot size; $\mathrm{F}_{\text {in }}$ is the measured flow rate and $\mathrm{C}$ represents absorption enhancement factor due to the light scattering of filter.

The wavelength dependence of black carbon was calculated in the range of $370-950 \mathrm{~nm}$ by the following equation.

$b_{a b s}=\lambda^{-A A E}$

where $\lambda$ is the chosen wavelength and AAE is the Ängström exponent.

Source apportionment of black carbon was based on the method from Sandradewi et al. (2008), which assumed that biomass burning (BB) and fossil fuels (FF) combustion were the two sources to black carbon. The calculation is expressed as follows. $b_{\mathrm{abs}}(470 \mathrm{~nm})=b_{\mathrm{abs}}(470 \mathrm{~nm})_{\mathrm{ff}}+b_{\mathrm{abs}}(470 \mathrm{~nm})_{\mathrm{bb}}$

$b_{\mathrm{abs}}(950 \mathrm{~nm})=b_{\mathrm{abs}}(950 \mathrm{~nm})_{\mathrm{ff}}+b_{\mathrm{abs}}(950 \mathrm{~nm})_{\mathrm{bb}}$

$\frac{b_{\mathrm{abs}}(470 \mathrm{~nm})_{\mathrm{bb}}}{b_{\mathrm{abs}}(950 \mathrm{~nm})_{\mathrm{bb}}}=\left(\frac{470}{950}\right)^{-\alpha_{\mathrm{bb}}}$

$\frac{b_{\mathrm{abs}}(470 \mathrm{~nm})_{\mathrm{ff}}}{b_{\mathrm{abs}}(950 \mathrm{~nm})_{\mathrm{ff}}}=\left(\frac{470}{950}\right)^{-\alpha_{\mathrm{ff}}}$

Then, the contribution from biomass burning to black carbon (BB, \%) can be obtained.

$\mathrm{BB}(\%)=\frac{b_{\mathrm{abs}}(950 \mathrm{~nm})_{\mathrm{bb}}}{b_{\mathrm{abs}}(950 \mathrm{~nm})}$

The $\alpha$ values of black carbon depended on source types, combustion conditions, aerosol aging, and coating thickness (Martinsson et al. 2015). Here, $\alpha_{\mathrm{ff}}=1$ for fossil fuels combustion and $\alpha_{\mathrm{bb}}=2$ for biomass burning were adopted in this study (Martinsson et al. 2017).

At each site, the aethalometer is co-located with a $\mathrm{PM}_{2.5}$ monitor. $\mathrm{PM}_{2.5}$ concentrations were continuously measured by TEOM-1405-D dual channel particle on-line monitor (Thermo Fisher Scientific, USA) through a $\mathrm{PM}_{2.5}$ cyclone inlet at a flow rate of $16.7 \mathrm{~L} \mathrm{~min}^{-1}$.

\section{Spatial correlation analysis by Global Moran's I}

Global Moran's I is a correlation coefficient to examine whether the spatial autocorrelation is dispersed, random, or clustered, which depends on the spatial weight matrices and reflects the strength of the geographical relationship between observations. Given a set of elements and associated attributes, Global Moran's I assesses the significance of the index by Moran's I index value, $\mathrm{z}$-score value and $\mathrm{p}$-value. It can be expressed as follows.

$I=\frac{n}{S_{0}} \frac{\sum_{i=1}^{n} \sum_{j=1}^{n} W_{i, j}\left(x_{i}-\bar{X}\right)\left(x_{j}-\bar{X}\right)}{\sum_{i=1}^{n}\left(x_{i}-\bar{X}\right)^{2}}$

where $w_{i, j}$ is the spatial weight coefficient between spatial elements $i$ and $j, x$ is the variable of interest, $n$ is the total number of spatial elements, and $S_{0}$ represents the sum of all spatial weight coefficients.

$S_{0}=\sum_{i=1}^{n} \sum_{j=1}^{n} W_{i, j}$

Values of Global Moran's I range from -1 to 1 after variance normalization and represents different meanings 
of spatial correlation. The expected index values are compared to the observed index values. Z-score and $p$-value are calculated to indicate whether the difference is statistically significant when the elements data and its variance were considered. As a result of the inferential statistics, the index values only can be interpreted under the null hypothesis. If the $p$-value is statistically significant $(p<0.05)$, the null hypothesis can be rejected and vice versa. The positive (negative) z-score indicates the spatial distribution of high and/or low values in the dataset is more spatially clustered (dispersed) than expected.

(i) Moran's $I>0$, indicates a positive spatial correlation and perfect clustering of similar values.

(ii) Moran's $I=0$, indicates the space is no autocorrelation (perfect randomness);

(iii) Moran's $I<0$, indicates a negative spatial correlation and clustering of dissimilar values.

\section{Results and discussion}

\section{Variations of regional $\mathrm{PM}_{2.5}$ and black carbon before, during, and after the COVID-19 lockdown}

The whole study period from January to April was divided into four stages. (i) Pre-Lock (Pre-Lock, 1st January to 22nd
January), which refers to the period before the outbreak of COVID-19 pandemic. People's daily activities and industrial productions were normal and this period included the Chinese Spring Festival travel rush. (ii) Strict-Lock (S-Lock, 23rd January to 28th February), which represents the strictest control period when people were required to stay at home and almost all the unnecessary production and human activities were prohibited. (iii) Lightened-Lock (L-Lock, 1st March to 31st March), which represents the period that human activities gradually recovered. (iv) Post-Lock (PostLock, 1st April-30th April), which represents the period that human activities were almost back to normal when China's COVID-19 epidemic was fully controlled.

Figure 2 shows the variations of mean $\mathrm{PM}_{2.5}$ and black carbon concentrations at 9 sites in the Yangtze River Delta region during the four stages above. The reduction extents of black carbon and $\mathrm{PM}_{2.5}$ concentrations compared to PreLock were calculated as below.

$\mathrm{RC}_{\mathrm{PM} 2.5 / \text { black carbon }}=\frac{\mathrm{C}_{\mathrm{PM} 2.5 / \text { black carbon, Pre-Lock }}-\mathrm{C}_{\mathrm{PM} 2.5 / \text { black carbon, } \mathrm{x}}}{\mathrm{C}_{\mathrm{PM} 2.5 / \text { black carbon, Pre-Lock }}}$

where $x$ presents one of the latter three stages.

As shown in Fig. 2a and Table $\mathrm{S} 2, \mathrm{PM}_{2.5}$ showed a spatial difference of Jiangsu province $>$ Anhui province $\approx$ Shanghai $>$ Zhejiang province during Pre-Lock. While during the latter three stages, $\mathrm{PM}_{2.5}$ showed similar concentration levels
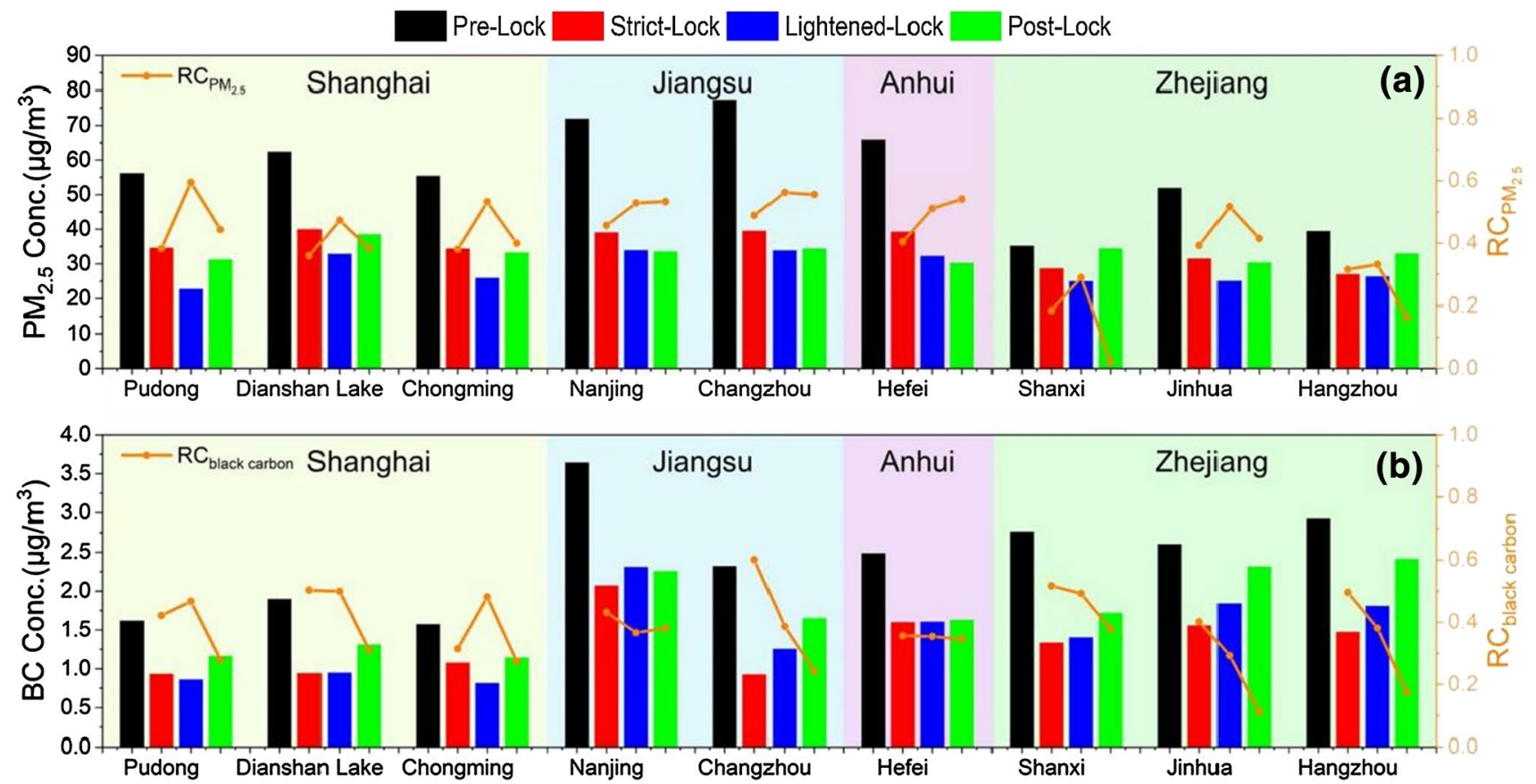

Fig. 2 Mean concentrations of $\mathrm{PM}_{2.5}$ and black carbon during the four periods, i.e., Pre-Lock, S-Lock, L-Lock, and Post-Lock. The orange lines denote the ratios of mass concentration reduction ( $\mathrm{RC}_{\mathrm{PM} 2.5}$ or $\left.\mathrm{RC}_{\text {black carbon }}\right)$ during the latter three periods compared to
Pre-Lock. Both $\mathrm{PM}_{25}$ and black carbon decreased during the lockdown periods at all 9 sites while they rebounded during the Post-Lock period. The COVID-19 lockdown policies had significantly restricted human activities and substantially reduced the levels of air pollutants 
across the Yangtze River Delta and were much lower than that during Pre-Lock.

Due to the lockdown policies, human activities and industrial productions were limited. Overall, apart from Shanxi and Hangzhou, the reduction of $\mathrm{PM}_{2.5}$ at the other sites reached approximately $40 \sim 60 \%$ in the latter three periods. $\mathrm{PM}_{2.5}$ reductions in Nanjing, Changzhou, and Hefei were stronger than the other sites, while Shanxi and Hangzhou showed the lowest reductions extents. Different city industrial structures may be an important reason for the different reduction extents. Primary emissions of $\mathrm{PM}_{2.5}$ from traffic and industrial processes, especially in urban Nanjing, Changzhou and Hefei were substantially reduced. The reduction extents in Nanjing, Changzhou, and Hefei reached at $49 \%, 46 \%$, and $40 \%$ during Pre-Lock, respectively. As the famous tourist and ecological cities, Shanxi and Hangzhou were characterized of relatively low industrial capacity and the impact of lockdown on reducing the air pollutants emissions were less significant than the other cities, resulting in the value of $\mathrm{RC}_{\mathrm{PM} 2.5}$ less than $40 \%$. This indicated that the cessation of human and industrial activities had produced conspicuous effects in reducing air pollution, especially in densely populated transportation and industrial areas.

As for black carbon, it showed a similar temporal trend of Pre-Lock > Post-Lock > L-Lock $\approx \mathrm{S}$-Lock as $\mathrm{PM}_{2.5}$ at all nine sites (Fig. 2b and Table S2). During Pre-Lock, besides the business-as-usual human activities, this period included the world's largest annual migration event, i.e., the Spring Festival exodus. This explained the highest black carbon concentrations compared to the latter three periods. Among the nine sites, black carbon in Nanjing was the highest, followed by Hangzhou, Shanxi, Jinhua, Hefei, and Changzhou, while the three sites of Shanghai showed the lowest black carbon concentrations. During the two lockdown periods, motor vehicle miles traveled were greatly reduced and most factories were temporarily closed. Thus, primary emission sources of black carbon were expected drastically reduced. Values of $\mathrm{RC}_{\text {black carbon }}$ all reached $40-50 \%$ during S-Lock and L-Lock, much higher than those during Post-Lock. Black carbon was still the highest in Nanjing, followed by Hefei, Shanxi, Jinhua, and Hangzhou while black carbon in Changzhou decreased the most and reached the similar levels as the three sites in Shanghai. As an important industrial and manufacturing base in the Yangtze River Delta, the control policies had caused tremendous primary emission reductions on the transportation, industry, and manufacturing sectors in Changzhou, resulting in a maximum $\mathrm{RC}_{\text {black carbon }}$ of approximate $60 \%$. During Post-Lock, black carbon rebounded at all nine cities compared to the previous two lockdown periods. Values of $\mathrm{RC}_{\text {black carbon }}$ were approximately $20 \sim 40 \%$, indicating black carbon was still lower than that during Pre-Lock. This was mainly caused by the incomplete recovery of work and industrial productions.
As a comparison, $\mathrm{PM}_{2.5}$ did not rebound as significantly as black carbon, suggesting that not only lockdown policies were crucial for the reduction of primary emissions, but also the sources of $\mathrm{PM}_{2.5}$ before and after lockdown had changed significantly (Huang et al. 2021; Le et al. 2020; Zheng et al. 2020), which will be further discussed.

\section{Diurnal patterns of black carbon}

Figure 3 shows the diurnal patterns of black carbon at the 9 Yangtze River Delta sites during the four stages. During PreLock, black carbon showed a bimodal distribution of peaks in the morning and evening rush hours except at Chongming. In contrast, the bimodal patterns during S-Lock and L-Lock were not as obvious as Pre-Lock, which were mainly due to the restriction of the traffic sector. What's more, peaks in the morning were approximately 1-2 h earlier than Pre-Lock, which may be related to emissions from vehicles for essential life support and municipal works. During Post-Lock, the bimodal patterns of black carbon emerged again owing to the gradual recovery of transportation. At late night, high black carbon concentrations were outstanding at almost all sites. Heavy-duty diesel trucks mostly worked at nighttime, especially observed at the urban sites including Pudong, Nanjing, Hefei, Changzhou, and BJ, contributing to substantial carbonaceous emissions. As for Chongming, which is a background coastal site with rare local emissions from industries as mentioned earlier, its diurnal variation of black carbon was different from those of the city sites, showing a unimodal distribution during Pre-Lock. Natural and agriculture-related biomass burning, as well as residential activities dominated the black carbon sources (Becerril-Valle et al. 2017; Wei et al. 2017). The intensification of black carbon due to these activities usually reached a maximum at noon.

\section{Changes of the relationship between black carbon and $\mathbf{P M}_{2.5}$}

The sources of black carbon were predominantly from primary emissions via incomplete combustion of various fossil fuels and biomass, while the sources of $\mathrm{PM}_{2.5}$ were from both primary emissions and secondary formations. Previous studies have shown that $\mathrm{PM}_{2.5}$ and black carbon could be well correlated in areas with strong primary emissions such as the city centers of Beijing and Shanghai (Liu et al. 2018; Wei et al. 2020). However, their relationship could be changed due to varying emissions.

Black carbon exhibited significant correlations with $\mathrm{PM}_{2.5}$ except at Shanxi and Jinhua during Pre-Lock (Fig. S1 and Table S3). As mentioned above, the Pre-Lock stage included the Chinese Spring Festival travel rush, during which vehicle emissions were greatly enhanced, and hence strengthened the relationship between primary emissions 

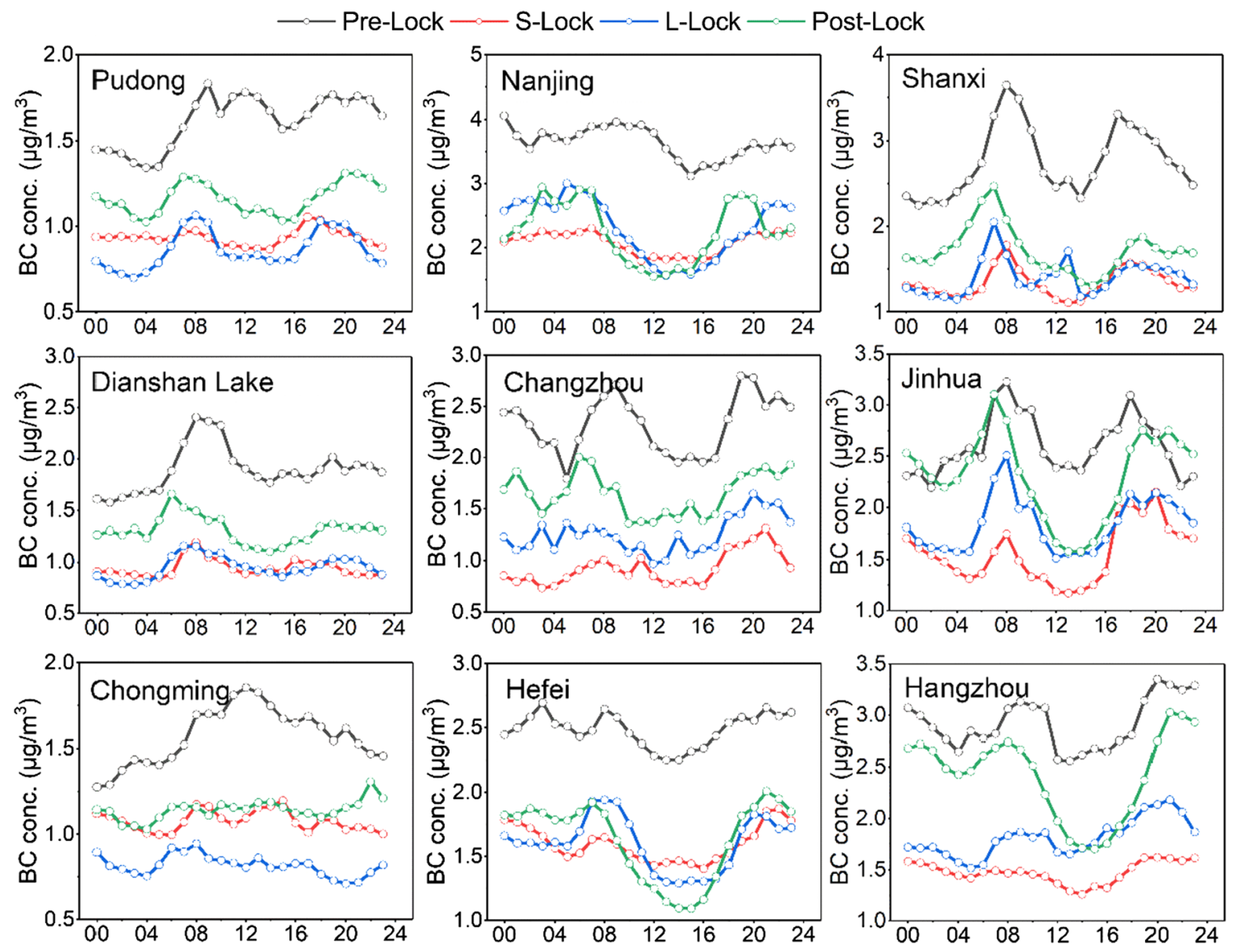

Fig. 3 Diurnal patterns of black carbon at nine sites during four stages. The bimodal patterns were weakened mainly due to the restriction of the traffic sector except at Chongming. After the lockdown, the bimodal patterns emerged again as the recovery of transportation

and fine particles. As for Shanxi and Jinhua, the sources of $\mathrm{PM}_{2.5}$ were dominated by secondary formation rather than primary emissions which were weaker than the other sites. Divergent sources of $\mathrm{PM}_{2.5}$ and black carbon explained their insignificant correlation at Shanxi and Jinhua. While during the S-Lock and L-Lock stages, the correlations between black carbon and $\mathrm{PM}_{2.5}$ were no longer as significant as those during Pre-Lock. Due to the lockdown policies, traffic activities and industrial productions were limited, causing reduced emissions of black carbon and gaseous precursors of $\mathrm{PM}_{2.5}$ with different extents ( $\mathrm{Li}$ et al. 2020). Specifically, the lowered traffic emissions had strongly reduced the magnitudes of black carbon. On the other hand, $\mathrm{O}_{3}$ during the lockdown period became much higher compared to those before the lockdown. The enhanced $\mathrm{O}_{3}$ concentration throughout the country had promoted more efficient secondary aerosol formation (Feng et al. 2020; He et al. 2020; Liu et al. 2020; Wang et al. 2021b; Zhu et al. 2021). This explained the weakened correlations between black carbon and $\mathrm{PM}_{2.5}$ observed at most sites. During Post-Lock, the partially recovered traffic activities and industrial productions resulted in reduced black carbon emissions compared to Pre-Lock. The correlations between black carbon and $\mathrm{PM}_{2.5}$ remained at relatively low levels at most sites.

\section{Source apportionment of regional black carbon}

Sources of black carbon at the regional scale were apportioned based on the aethalometer method given in, with an assumption that black carbon was dominated by fossil fuel combustion and biomass burning (See methods in "Spatial c orrelation analysis by Global Moran's I" Section). In general, the Absorption Ångström Exponent (AAE) of black carbon from biomass burning exhibited higher values (1.6-2.0) than that of fossil fuel combustion (0.8-1.1) (Kirchstetter et al. 2004; Sandradewi et al. 2008; Schnaiter et al. 2003). As shown in Fig. S2, Absorption Angström Exponent of black carbon at selected sites showed consistent trends with the percentage of black carbon contributed by biomass burning, indicating the source appointment results were credible.

Figure S3 and Table S4 show the source apportionment results of black carbon during the four periods. During PreLock, fossil fuels combustion was the dominate source at almost all sites, contributing more than $90 \%$ of black carbon. 
A small fraction of approximate 3-18\% of black carbon was ascribed to biomass burning which could be due to straw burning and rural household cooking except at Chongming. Compared to Pre-Lock, black carbon from fossil fuels combustion during S-Lock showed decreases at most sites while the relative contribution of biomass burning increased about $10 \%$, which was evidently attributed to the lockdown policies that constrained traffic and industrial activities. During L-Lock and Post-Lock, the contribution from fossil fuels combustion to black carbon turned as similar as that of Pre-Lock, indicating the recovery of economic activities. Chongming, as a rural site in eastern Shanghai, is located in the coastal region with low traffic and industrial emissions (Table S1). Biomass burning contributed about $21-27 \%$ to black carbon at this site, which was much higher than the other sites. Earlier study also demonstrated that biomass and wood burning for cooking, heating, living, and agricultural activities in winter contributed the largest fraction $(35.1 \pm 3.4 \%)$ of black carbon in $\mathrm{PM}_{2.5}$ (Wei et al. 2017).

\section{Spatial correlation of black carbon in the Yangtze River Delta}

Previous studies have demonstrated that air pollution in China exhibited some typical regional characteristics that air pollutants in one city affected the air quality of neighboring cities. Therefore, there may be a strong spatial correlation between the air pollutants of geographically nearby cities (Chan and Yao 2008). Using the Moran index and a spatial economic model, 73 cities in China, mainly Beijing, Tianjin, Hebei, and the Yangtze River Delta, were analyzed and significant spatial correlations were found for $\mathrm{PM}_{2.5}$ mass concentrations among neighboring cities (Hao and Liu 2016). Han et al. (2019) also showed that the air quality index (AQI) of Chinese cities had significantly positive spatial correlation. Furthermore, Global Moran's I has been applied for the analysis of spatial correlations between ambient air pollution and outward foreign direct investment (Zhou and $\mathrm{Li}$
2021), diseases (Wang et al. 2015), and unequal residential exposure (Verbeek 2019).

To probe the spatial relationship of black carbon in the Yangtze River Delta region, Global Moran's I with daily resolution was performed for black carbon and sample data that did not pass the $p$-test $(p<0.05)$ were considered invalid. In the samples that passed the p-test, a positive $Z$ value (Z-score) indicated an aggregation effect and a negative $\mathrm{Z}$ value indicated a dispersion effect. Larger Global Moran's I value represented higher clustering strength and vice versa.

Figure 4 and Table S5 show the Global Moran's I results for black carbon. For samples that passed the p-test during Pre-Lock, Global Moran's I and Z-score exhibited a maximum of 0.53 (2.5) and a minimum of 0.19 (1.89). While during S-Lock, Global Moran's I and Z-score exhibited a maximum of 0.69 (3.52) and a minimum was of -0.64 $(-2.23)$. More black carbon samples passed the $p$-test during the S-Lock (47\%) than during Pre-Lock (32\%) with higher Moran's I and Z values, indicating that black carbon showed stronger clustering within the Yangtze River Delta during S-Lock. During L-Lock, spatial correlation and clustering strength decreased compared to S-Lock, with a maximum of 0.61 and a minimum of 0.03 for Global Moran's I and a maximum of 2.68 and a minimum of 1.81 for Z-score. During Post-Lock, only $30 \%$ of the sample data passed the p-test, with spatial correlation and clustering strength slightly higher than Pre-Lock and lower than L-Lock. Overall, black carbon showed moderate spatial correlation in the Yangtze River Delta and S-Lock and L-Lock showed more significant spatial correlation and clustering strength than Pre-Lock and Post-Lock.

During Pre-Lock when the Chinese Spring Festival travel rush significantly increased transportation emissions, the black carbon emissions were expected to be heterogeneous in the Yangtze River Delta due to large differences of passenger flows among various regions and this explained the insignificant spatial correlation of black carbon. As the lockdown policies significantly reduced the black carbon emissions across-the-board, black carbon concentrations
Fig. 4 Global Moran's I results for black carbon in the Yangtze River Delta region during the four periods. During the lockdown, more samples passed the p-test with higher Moran's I and $\mathrm{Z}$ values than the other periods. This indicated more clustering of black carbon during the lockdown, owing to the across-theboard emission reductions in the Yangtze River Delta

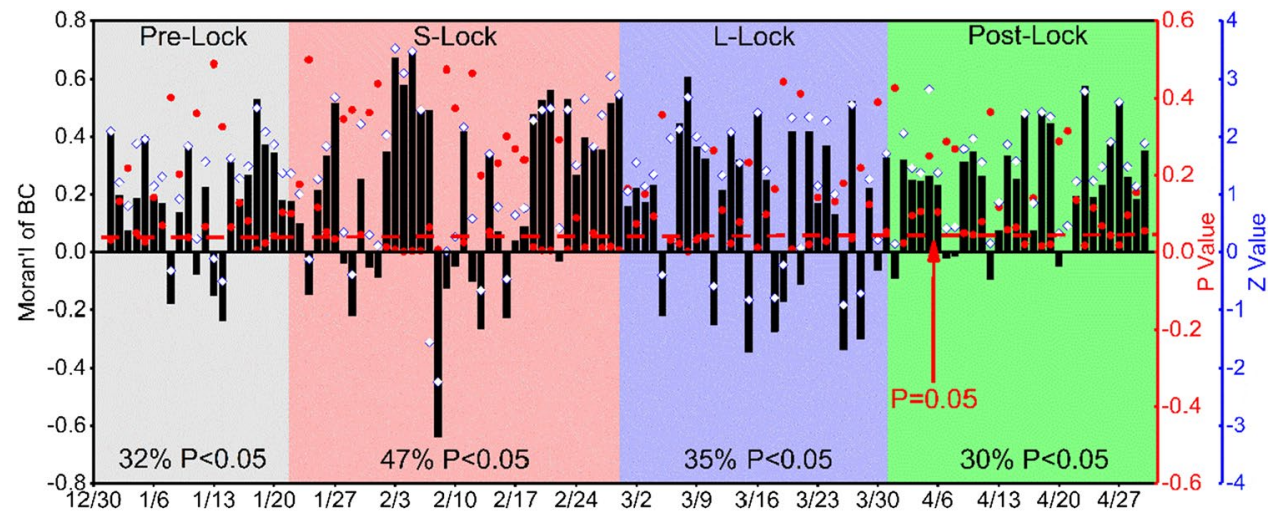


observed at various regions were of similar levels, resulting in a strong spatial correlation of black carbon in the Yangtze River Delta. As for Post-Lock, the spatial correlation of black carbon was lowered due to the inconsistent recovery policies enacted by local authorities according to actual situations.

The Global Moran's I results were verified by cluster heat maps as shown in Fig. S4-S7. The color and number in each cell represent the daily black carbon concentration at each site. Similar color shades, values and expression mode (the line on the top of figure) indicate stronger clustering. It can be seen that cells exhibited more similar colors, values and expression mode during S-Lock and L-Lock than during Pre-Lock and Post-Lock, corroborating the results of the Global Moran's I analysis.

\section{Conclusion}

This study revealed the characteristics of black carbon measured at 9 sites in the Yangtze River Delta region of Eastern China during the COVID-19 pandemic. The regional $\mathrm{PM}_{2.5}$ and black carbon concentrations decreased $40-60 \%$ and 40-50\% from 23 January to 28 February when the strictest lockdown was enacted. Black carbon rebounded after the lockdown along with the gradual recovery of human activities. The diurnal pattern of black carbon showed a bimodal distribution in the morning and evening rush hours during normal periods. During the lockdown, the bimodal distribution was weakened and the morning peak appeared about 1-2 h earlier. Fossil fuels combustion dominated the sources of black carbon with a high contribution of around $90 \%$. The relative contribution of biomass burning increased 5-10\% during the lockdown.

The strong relationship between $\mathrm{PM}_{2.5}$ and black carbon before the lockdown demonstrated that strong primary emissions partly from the Chinese Spring Festival rush heavily influenced the air quality in the Yangtze River Delta, while the lowered correlations between them during and after the lockdown suggested the sources of $\mathrm{PM}_{2.5}$ were greatly changed. Based on the Global Moran's Index analysis, the spatial correlation of black carbon in the Yangtze River Delta region displayed stronger clustering strength during the lockdown than the other periods. The nationwide lockdown policy induced similar black carbon concentrations and diurnal patterns over the Yangtze River Delta, hence enhancing their spatial correlations. This study demonstrates the regional scale emission control is the only way to effectively mitigate the black carbon pollution. In the future, adjustment of the energy structure should be the priority as well as the continuous development of 'Green Public Transit System' (e.g., new energy vehicles and subway) in the Yangtze River Delta region.
Supplementary Information The online version contains supplementary material available at https://doi.org/10.1007/s10311-021-01327-3.

Acknowledgements This work was financially supported by the National Key R\&D Plan programs (2018YFC0213105), the National Natural Science Foundation of China (91644105), and the Natural Science Foundation of Shanghai (18230722600, 19ZR1421100, 20ZR1422000).

Author Contributions Kan Huang and Qingyan Fu designed this study. Hao Li and Kan Huang analyzed data and wrote the paper. Yanfen Lin, Jia Chen, Xudong Tian, Qian Tang, Qingchuan Song, and Zhen Wei collected the data. All have commented and reviewed the paper.

\section{Declarations}

Conflict of interest The authors declare that they have no conflict of interest.

\section{References}

Bauwens M, Compernolle S, Stavrakou T, Müller J-F, van Gent J, Eskes H et al. (2020) Impact of coronavirus outbreak on NO2 pollution assessed using TROPOMI and OMI observations. https:// doi.org/10.1029/2020GL087978

Becerril-Valle M, Coz E, Prévôt ASH, Močnik G, Pandis SN, Sánchez de la Campa AM et al (2017) Characterization of atmospheric black carbon and co-pollutants in urban and rural areas of Spain. Atmos Enviro 169:36-53

Bond TC, Doherty SJ, Fahey DW, Forster PM, Berntsen T, DeAngelo $\mathrm{BJ}$ et al (2013) Bounding the role of black carbon in the climate system: a scientific assessment. J Gerontol Ser A Biol Med Sci 118:5380-5552. https://doi.org/10.1002/jgrd.50171

Briggs NL, Long CM (2016) Critical review of black carbon and elemental carbon source apportionment in Europe and the United States. Atmos Environ 144:409-427. https://doi.org/10.1016/j. atmosenv.2016.09.002

Cai M, Guy C, Héroux M, Lichtfouse E, An C (2021) The impact of successive COVID-19 lockdowns on people mobility, lockdown efficiency, and municipal solid waste. Environ Chem Lett. https://doi.org/10.1007/s10311-021-01290-z.10.1007/ s10311-021-01290-z

Chan CK, Yao X (2008) Air pollution in mega cities in China. Atmos Environ 42:1-42

Chang YH, Huang RJ, Ge XL, Huang XP, Hu JL, Duan YS et al (2020) Puzzling haze events in china during the coronavirus (COVID19) shutdown. Geophys Res Lett. https://doi.org/10.1029/2020G L088533

Evangeliou N, Platt SM, Eckhardt S, Lund Myhre C, Laj P, AladosArboledas L et al (2021) Changes in black carbon emissions over Europe due to COVID-19 lockdowns. Atmos Chem Phys 21:2675-2692. https://doi.org/10.5194/acp-21-2675-2021.10. 5194/acp-21-2675-2021

Feng T, Zhao S, Zhang X, Wang Q, Liu L, Li G et al (2020) Increasing wintertime ozone levels and secondary aerosol formation in the Guanzhong basin, central China. Sci Total Environ 745:140961

Gettelman A, Lamboll R, Bardeen CG, Forster PM, Watson-Parris D (2021) Climate impacts of COVID-19 induced emission changes. Geophys Res Lett. https://doi.org/10.1029/2020GL091805

Goel V, Hazarika N, Kumar M, Singh V, Thamban NM, Tripathi SN (2021) Variations in Black Carbon concentration and sources during COVID-19 lockdown in Delhi. Chemosphere 270:129435 
Han X, Li H, Liu Q, Liu F, Arif A (2019) Analysis of influential factors on air quality from global and local perspectives in China. Environ Pollut 248:965-979

Hao Y, Liu Y-M (2016) The influential factors of urban PM2.5 concentrations in China: a spatial econometric analysis. J Clean Prod 112:1443-1453

He G, Pan Y, Tanaka T (2020) The short-term impacts of COVID19 lockdown on urban air pollution in China. Nat Sustain 3:1005-1011. https://doi.org/10.1038/s41893-020-0581-y.10. 1038/s41893-020-0581-y

Huang K, Zhuang G, Lin Y, Wang Q, Fu JS, Zhang R et al (2012) Impact of anthropogenic emission on air quality over a megacity - revealed from an intensive atmospheric campaign during the Chinese Spring Festival. Atmos Chem Phys 12:1163111645. https://doi.org/10.5194/acp-12-11631-2012.10.5194/ acp-12-11631-2012

Huang X, Ding AJ, Gao J, Zheng B, Zhou DR, Qi XM et al (2021) Enhanced secondary pollution offset reduction of primary emissions during COVID-19 lockdown in China. Natl Sci Rev. https:// doi.org/10.1093/nsr/nwaa137

Kirchstetter TW, Novakov T, Hobbs PV (2004) Evidence that the spectral dependence of light absorption by aerosols is affected by organic carbon. J Gerontol Ser A Biol Med Sci. https://doi.org/ 10.1029/2004JD004999

Le TH, Wang Y, Liu L, Yang JN, Yung YL, Li GH et al (2020) Unexpected air pollution with marked emission reductions during the COVID-19 outbreak in China. Science 369:702

Li L, Li Q, Huang L, Wang Q, Zhu AS, Xu J et al (2020) Air quality changes during the COVID-19 lockdown over the Yangtze River Delta Region: an insight into the impact of human activity pattern changes on air pollution variation. Sci Total Environ. https://doi. org/10.1016/j.scitotenv.2020.139282

Lin Y-C, Zhang Y-L, Xie F, Fan M-Y, Liu X (2021) Substantial decreases of light absorption, concentrations and relative contributions of fossil fuel to light-absorbing carbonaceous aerosols attributed to the COVID-19 lockdown in east China. Environ Pollut 275:116615

Liu T, Wang X, Hu J, Wang Q, An J-y, Gong K et al (2020) Driving forces of changes in air quality during the COVID-19 lockdown period in the yangtze River Delta Region, China. Environ Sci Technol Lett 7:779-786. https://doi.org/10.1021/acs.estlett.0c005 11

Liu Y, Yan C, Zheng M (2018) Source apportionment of black carbon during winter in Beijing. Sci Total Environ 618:531-541. https:// doi.org/10.1016/j.scitotenv.2017.11.053.10.1016/j.scitotenv.2017. 11.053

Martinsson J, Abdul Azeem H, Sporre MK, Bergström R, Ahlberg E, Öström E et al (2017) Carbonaceous aerosol source apportionment using the Aethalometer model - evaluation by radiocarbon and levoglucosan analysis at a rural background site in southern Sweden. Atmos Chem Phys 17:4265-4281. https://doi.org/10. 5194/acp-17-4265-2017.10.5194/acp-17-4265-2017

Martinsson J, Eriksson AC, Nielsen IE, Malmborg VB, Ahlberg E, Andersen $C$ et al (2015) Impacts of combustion conditions and photochemical processing on the light absorption of biomass combustion aerosol. Environ Sci Technol 49:14663-14671. https://doi. org/10.1021/acs.est.5b03205.10.1021/acs.est.5b03205

Meng J, Li Z, Zhou R, Chen M, Li Y, Yi Y et al (2021) Enhanced photochemical formation of secondary organic aerosols during the COVID-19 lockdown in Northern China. Sci Total Environ 758:143709

Sandradewi J, Prevot ASH, Szidat S, Perron N, Alfarra MR, Lanz VA et al (2008) Using aerosol light absorption measurements for the quantitative determination of wood burning and traffic emission contributions to particulate matter. Environ Sci Technol 42:33163323. https://doi.org/10.1021/es702253m
Schnaiter M, Horvath H, Mohler O, Naumann KH, Saathoff H, Schock OW (2003) UV-VIS-NIR spectral optical properties of soot and soot-containing aerosols. J Aerosol Sci 34:1421-1444. https://doi. org/10.1016/S0021-8502(03)00361-6

Sharma VK, Jinadatha C, Lichtfouse E (2020) Environmental chemistry is most relevant to study coronavirus pandemics. Environ Chem Lett 18:993-996. https://doi.org/10.1007/s10311-02001017-6.10.1007/s10311-020-01017-6

Tanvir A, Javed Z, Jian Z, Zhang SB, Bilal M, Xue RB et al (2021) Ground-based MAX-DOAS observations of tropospheric NO2 and HCHO During COVID-19 Lockdown and spring festival over Shanghai. China Remote Sens. https://doi.org/10.3390/rs130 30488

Tian HY, Liu YH, Li YD, Wu CH, Chen B, Kraemer MUG et al (2020) An investigation of transmission control measures during the first 50 days of the COVID-19 epidemic in China. Science 368:638

Verbeek T (2019) Unequal residential exposure to air pollution and noise: a geospatial environmental justice analysis for Ghent, Belgium. SSM - Popul Health 7:100340

Wang C, Horby PW, Hayden FG, Gao GF (2020a) A novel coronavirus outbreak of global health concern. Lancet 395:470-473

Wang H, Miao Q, Shen L, Yang Q, Wu Y, Wei H et al (2021a) Characterization of the aerosol chemical composition during the COVID19 lockdown period in Suzhou in the Yangtze River Delta, China. J Environ Sci 102:110-122. https://doi.org/10.1016/j.jes.2020.09. 019

Wang L, Li M, Yu S, Chen X, Li Z, Zhang Y et al (2020b) Unexpected rise of ozone in urban and rural areas, and sulfur dioxide in rural areas during the coronavirus city lockdown in Hangzhou, China: implications for air quality. Environ Chem Lett 18:1713-1723

Wang W, Ying Y, Wu Q, Zhang H, Ma D, Xiao W (2015) A GIS-based spatial correlation analysis for ambient air pollution and AECOPD hospitalizations in Jinan, China. Resp Med 109:372-378

Wang Y, Li Z, Wang Q, Jin X, Yan P, Cribb M et al (2021b) Enhancement of secondary aerosol formation by reduced anthropogenic emissions during Spring Festival 2019 and enlightenment for regional PM2.5 control in Beijing. Atmos Chem Phys 21:915-926. https://doi.org/10.5194/acp-21-915-2021.10.5194/ acp-21-915-2021

Wang ZL, Huang X, Ding K, Ren CH, Cao L, Zhou DR et al (2021c) Weakened aerosol-PBL interaction during COVID-19 Lockdown in Northern China. Geophys Res Lett. https://doi.org/10.1029/ 2020GL090542

Wei C, Wang MH, Fu QY, Dai C, Huang R, Bao Q (2020) Temporal characteristics and potential sources of black carbon in megacity Shanghai, China. J Geophys Res Atmos. https://doi.org/10.1029/ 2019jd031827.10.1029/2019JD031827

Wei N, Wang G, Zhouga D, Deng K, Feng J, Zhang Y et al (2017) Source apportionment of carbonaceous particulate matter during haze days in Shanghai based on the radiocarbon. J Radioanal Nucl Chem 313:145-153. https://doi.org/10.1007/s10967-017-5267-1. 10.1007/s10967-017-5267-1

Xu L, Zhang J, Sun X, Xu SC, Shan M, Yuan Q et al (2020) Variation in concentration and sources of black carbon in a megacity of China during the COVID-19 pandemic. Geophys Res Lett. https:// doi.org/10.1029/2020GL090444

Yuan Q, Qi B, Hu D, Wang J, Zhang J, Yang H et al (2021) Spatiotemporal variations and reduction of air pollutants during the COVID19 pandemic in a megacity of Yangtze River Delta in China. Sci Total Environ 751:141820

Zhao F, Liu C, Cai Z, Liu X, Bak J, Kim J et al (2021) Ozone profile retrievals from TROPOMI: implication for the variation of tropospheric ozone during the outbreak of COVID-19 in China. Sci Total Environ 764:142886

Zhao SY, Tie XX, Cao JJ, Li N, Li GH, Zhang Q et al (2015) Seasonal variation and four-year trend of black carbon in the Mid-west 
China: the analysis of the ambient measurement and WRF-Chem modeling. Atmos Environ 123:430-439. https://doi.org/10.1016/j. atmosenv.2015.05.008

Zheng H, Kong S, Chen N, Yan Y, Liu D, Zhu B et al (2020) Significant changes in the chemical compositions and sources of PM2.5 in Wuhan since the city lockdown as COVID-19. Sci Total Environ 739:140000

Zheng S, Fu Y, Sun Y, Zhang C, Wang Y, Lichtfouse E (2021) High resolution mapping of nighttime light and air pollutants during the COVID-19 lockdown in Wuhan. Environ Chem Lett 19:3477-3485. https://doi.org/10.1007/s10311-021-01222-x.10. 1007/s10311-021-01222-x

Zhou A, Li J (2021) Analysis of the spatial effect of outward foreign direct investment on air pollution: evidence from China. Environ
Sci Pollut Res. https://doi.org/10.1007/s11356-021-13960-0.10. 1007/s11356-021-13960-0

Zhu J, Chen L, Liao H, Yang H, Yang Y, Yue X (2021) Enhanced PM2.5 decreases and O3 increases in China during COVID-19 lockdown by aerosol-radiation feedback._https://doi.org/10.1029/ 2020GL090260

Publisher's Note Springer Nature remains neutral with regard to jurisdictional claims in published maps and institutional affiliations. 